\title{
LUDICIDADE E EDUCAÇÃO INFANTIL: UM ELO NECESSÁRIO.
}

Carolline Rodrigues Guedes, Leonardo de Angelo Orlandi, José Milton de Lima, Márcia Regina Canhoto de Lima

Educação Física, Departamento de Educação Física, Faculdade de Ciências e Tecnologia UNESP - Presidente Prudente. CNPq/PIBIC. carolguedes11@hotmail.com.

\section{RESUMO}

Esta investigação assume como objeto de estudo e pesquisa a ludicidade no contexto da Educação Infantil. A pesquisa desenvolve-se em duas salas de Educação Infantil: Pré I e Pré II de uma Instituição Municipal, na cidade de Presidente Prudente e conta com a participação e colaboração de duas educadoras e quarenta crianças. $O$ interesse em pesquisar este tema surgiu a partir da constatação de que os atores escolares e familiares pouco sabem sobre as culturas infantis. $O$ referencial teórico predominante na pesquisa são os estudos da Sociologia da Infância. A metodologia utilizada caracteriza-se como Pesquisa do tipo etnográfico. Os resultados alcançados revelam que as professoras compreendem a importância do eixo ludicidade no desenvolvimento da criança, e os familiares valorizam o brincar tanto dentro de casa quanto na escola, e acreditam que a brincadeira é imprescíndivel para o desenvolvimento dos seus filhos.

Palavras-chave: Ludicidade, Culturas da Infância, Educação Infantil, Sociologia da Infância, Formação Continuada.

\section{INTRODUÇÃO E OBJETIVO}

No contexto educacional atual, a discussão sobre a infância, o brincar e a educação, tem sido intensificada. Nesse sentido, o presente trabalho assume como objeto de investigação a ludicidade no contexto da Educação Infantil, uma vez que professores e instituições educacionais ignoram a importância das culturas da infância, principalmente do eixo ludicidade, desvalorizando a voz das crianças e suas particularidades.

Diante dessa constatação, este trabalho foi desenvolvido em uma Instituição Municipal de Educação Infantil na cidade de Presidente Prudente e originou-se de um projeto maior intitulado: "Um caminho para a infância: saindo de encruzilhadas no contexto da Educação Infantil”. A pesquisa é composta por docentes e discentes dos Cursos de Pedagogia e Educação Física, da Faculdade de Ciências e Tecnologia - UNESP, Campus de Presidente Prudente, sendo todos integrantes do CEPELIJ - Centro de Estudo e Pesquisa em Educação, Ludicidade, Infância e Juventude e do Grupo de Pesquisa: "Cultura Corporal: saberes e fazeres", juntamente com a colaboração de educadores da instituição parceira. O trabalho é resultado de uma pesquisa de Iniciação Científica - PIBIC/CNPQ (Conselho Nacional de Desenvolvimento Científico e Tecnológico). 
No decorrer desta pesquisa, procuramos responder algumas questões referentes às culturas da infância, em especial um dos eixos estruturadores destas culturas, denominado por Sarmento (2004) de ludicidade, tanto no meio escolar como no meio familiar. As questões baseiam-se em: Quais as concepções de culturas da infância nesta instituição de Educação Infantil? Quais as concepções do brincar (eixo ludicidade) das professoras e pais/responsáveis? Qual a importância dada ao brincar na Educação Infantil e no cotidiano familiar?

A partir destas inquietações, o objetivo da pesquisa é o de analisar como são concebidas as Culturas da Infância e como é trabalhado um dos eixos estruturadores destas culturas, a ludicidade, tanto no meio escolar como no meio familiar. Para isso, o referencial teórico usado na pesquisa é a Sociologia da Infância, que considera a criança como ator social e produtor de cultura.

Segundo Sarmento (2002),

Conhecer as "nossas" crianças é decisivo para a revelação da sociedade, como um todo, nas suas contradições e complexidade. Mas é também a condição necessária para a construção de políticas integradas para a infância, capazes de reforçar e garantir direitos das crianças e a sua inserção plena na cidadania activa (SARMENTO, 2002, p. 1).

Deste modo, a pesquisa justificou-se na reflexão de que tanto os universitários quanto os educadores da instituição parceira, repensem suas práticas educativas e ampliem seus conhecimentos em relação à criança, oferecendo assim melhores condições e possibilidades de aprendizagem e desenvolvimento.

\section{METODOLOGIA}

Esta pesquisa buscou produzir saberes acerca da importância da valorização da ludicidade no contexto da Educação Infantil e familiar, destacando sua relevância para o desenvolvimento infantil, e foi autorizada pelo Comitê de Ética em Pesquisa com Seres Humanos processo $\mathrm{n}^{\circ}$ $102 / 2009$.

Deste modo, a pesquisa é de natureza qualitativa, uma vez que não se limita apenas em dados quantitativos, mas aborda variedades técnicas com a finalidade de apreender e interpretar os significados existentes no local de investigação, neste caso a instituição parceira.

A pesquisa quantitativa envolve uma abordagem naturalista, interpretativa do mundo circundante, o que significa que os pesquisadores estudam as coisas em seus cenários naturais, tentando entender, ou interpretar, os 
fenômenos em termos dos significados que as pessoas a eles conferem (SILVA, et al, 2010, p. 3).

Apoiada neste referencial qualitativo, esta pesquisa utiliza como procedimento técnico do tipo etnográfico.

Nos estudos etnográficos analisamos os aspectos simbólicos e culturais da ação social, os aspectos da existência que se revelam fundamentais na interpretação dos enunciados, as emoções e os sentimentos; como as pessoas envolvidas no estudo atribuem sentidos para os fatos da vida; como interpretam suas experiências ou estruturam o mundo no qual vivem (DELGADO; MÜLLER, 2005, p.169).

Além disto, a escolha deste percurso metodológico ocorreu considerando que parte dos estudos da infância, mesmo reconhecendo as crianças como atores sociais, ainda subestimam a capacidade criadora das crianças na sociedade e negligenciam a auscultação da voz das mesmas (SARMENTO; PINTO, 1997). Sendo assim, de acordo com Marchi (2010, p.194) "a etnografia tem sido apontada como metodologia particularmente adequada ao imperativo de 'dar voz' às crianças fazendo-as participar na produção dos dados sociológicos sobre suas maneiras de ser, sentir, agir e pensar".

Desta forma, André (1997, p.52) aponta que um relatório etnográfico deve conter "vinhetas narrativas que incluam descrições minuciosas de lugares, pessoas, situações observadas, descrições do que as pessoas fazem e dizem no seu dia-a-dia e citações literais de suas falas em entrevistas, depoimentos e documentos".

As observações foram feitas às sextas-feiras em turmas de Educação Infantil no Município de Presidente Prudente/SP, entre elas crianças de quatro e cinco anos de idade pertencentes ao Pré I e II, totalizando quarenta crianças e duas educadoras, no período das $9 \mathrm{~h} 00$ às $14 \mathrm{~h} 00$, com duração de 40 minutos em cada grupo. As coletas dos dados aconteciam a partir da observação participante em que os dados foram escritos no diário de campo. Neste diário foram anotados procedimentos para facilitar o processo de sistematização de dados, dando destaque para a data da observação, a turma escolar, os nomes das crianças, o espaço de realização das atividades, a temática do brincar, os aspectos desenvolvidos, as ações realizadas pelos alunos e atores escolares durante as aulas e especialmente durante os momentos de brincadeira. Além da utilização de gravações e fotografias para dar mais fidedignidade aos dados.

Durante o período de observação foi aplicado um questionário aberto às educadoras, com o intuito de identificar qual a visão de cada professora acerca do seu trabalho em sala de aula com 
as crianças e sua relação com o eixo "ludicidade". De acordo com Cunha (2007, p.72) o questionário pode "estabelecer combinações com outras técnicas de natureza qualitativa, mais abertas e menos estruturadas", como no nosso caso a observação participante dita acima. Em nome do rigor científico este questionário foi constituído por três fases/etapas em sua construção (adaptação): estudo pré- piloto, estudo piloto e estudo principal (CUNHA, 2007).

$\mathrm{Na}$ presente pesquisa também foi realizado entrevistas com os pais/responsáveis das crianças, com o objetivo de compreender como o eixo ludicidade é concebido no meio familiar, e se este eixo recebe sua devida importância, ou assume papel secundário e de pouco valor.

Neste sentido, a pesquisa procurou, através das observações, questionários, e entrevistas, identificar o olhar da instituição parceira para com as particularidades do Ensino Infantil e claramente compreender as dificuldades e limitações encontradas tanto pelas professoras, como pelas crianças no dia-a-dia no contexto educacional e familiar.

\section{RESULTADOS}

Conduzindo o olhar desta pesquisa, buscamos, por meio das observações, elucidar os trabalhos realizados na instituição parceira pelas professoras, relacionados ao eixo "ludicidade" e seus efeitos para com o desenvolvimento e aprendizagem das crianças. Para isso, procuramos responder algumas indagações: Como as professoras trabalhavam o eixo "ludicidade" no Ensino Infantil? Elas participavam das atividades junto às crianças mediando o processo de aprendizagem, ou apenas utilizavam as brincadeiras como forma de preencher o tempo? Elas davam prioridade às brincadeiras ou utilizavam-nas apenas quando sobrava tempo?

Nos primeiros momentos de observação na instituição parceira, as professoras mostraramse desinteressadas pelas atividades relacionadas ao eixo "ludicidade", uma vez que proporcionavam os momentos de brincadeiras para as crianças, contudo não mediavam estas atividades, dando a impressão de que as utilizavam apenas para passar o tempo, além de se refugiarem muitas vezes da realidade, realizando outras atividades paralelas.

Com o passar das observações, constatamos que as professoras começaram a mostrar maior interesse por estas atividades. Cada dia que passava, as professoras traziam brincadeiras diferentes e mais significativas, como a contextualização lúdica por meio da contação de histórias e começaram a participar ativamente das brincadeiras como mediadoras.

Através da aplicação dos questionários, que tinha como objetivo saber qual a visão de cada professora acerca do seu trabalho em sala de aula com as crianças e sua relação com o eixo 
"ludicidade", foi possível notar em suas respostas que, apesar do lúdico ter estado pouco presente em seu processo de formação, elas concebem o eixo ludicidade como necessário e eficaz para o desenvolvimento das crianças e sabem da sua relevância neste processo, apesar de muitas vezes não utilizarem brincadeiras em suas aulas.

No que diz respeito às crianças, foi perceptível durante as observações, o avanço que elas tiveram relacionados à fantasia do real, eixo intimamente ligado à ludicidade, no qual a criança constrói por meio da imaginação sua visão de mundo. Em uma das aulas, a professora Paula levou panelinhas, fogão entre outros objetos relacionados à cozinha para as crianças brincarem. Uma das crianças, no caso o Rogério, brincando com as panelinhas no fogão disse: "Tia, acho que caiu gordura no fogão". Logo após Rogério, Juliana derrubou o garfo no chão e disse: "Vou ter que pegar água para lavar", falas que mostram um elevado índice de imaginação destas crianças, que não era possível encontrar nos primeiros dias de observação.

Em relação aos familiares das crianças, foram realizadas entrevistas, com o propósito de saber qual a afinidade dos pais/responsáveis com seus filhos em relação à brincadeira em casa e na escola. Inicialmente perguntei aos pais/responsáveis se seus filhos tinham brinquedos e se eles brincavam muito.

Elaine: "Minha filha tem vários brinquedos, gosta de brincar muito, brinca de tudo, eu dou tempo pra ela brincar muito". Sueli: "A Laura brinca bastante com as bonecas dela, ela gosta mais de desenhar". $\quad$ Ivana: "A Suellen tem muitos brinquedos, e brinca bastante, brinca mais com os cadernos, canetas, pintura".

Em seguida perguntei se os pais/responsáveis brincavam com seus filhos.

Ana: "Não tenho tempo, nem paciência para brincar com a Carla, e o tempo que tenho fico jogando video game, mas, isso não impede que a Carla brinque, pois ela brinca sozinha". Marly: "Não tenho muito tempo, é mais o pai dela que brinca com ela, ela tem um irmão mais novo e preciso cuidar dele. Ela me pede para brincarmos juntas, mas eu digo: Agora não tenho tempo, porque eu tenho que cuidar da casa e do seu irmão mais novo".

Antonia: "Sim, eu brinco com a Ruth de escolinha, eu sou a professora e ela é a aluna! Também brincamos de boneca, a boneca é filha da Ruth e eu sou a avó da boneca! O tempo que eu tenho, eu brinco bastante com a minha filha".

Na sequência perguntei qual a opinião dos pais/responsáveis sobre o brincar na escola. 
Josefa: "A criança que está no pré pra mim, também precisa aprender a brincar, não somente a estudar! A brincadeira é tudo, é muito importante!".

Os outros não souberam responder a pergunta. A última pergunta foi se os filhos comentam as brincadeiras que aprendem na escola.

Helenice: "O Carlos fala das brincadeiras, ele diz assim: "mãe eu brinquei disso e disso com a professora". A brincadeira é muito importante, não é só estudar, só estudar, a infância da criança é muito importante". Jussara: "A Evelyn canta e brinca do mesmo jeitinho que foi passado na escola, o mesmo que ela aprende aqui ela faz em casa".

Dalva:

"O Luiz comenta as brincadeiras, e brinca em casa, ele é muito imaginativo".

Através destas entrevistas, pudemos notar que parte do ambiente familiar compreende a importância do brincar em casa e na escola, mas ainda é ausente a presença dos pais/responsáveis nas brincadeiras dos filhos, pois muitos não têm tempo para brincar com seus filhos pelo fato de trabalharem muito, ou até mesmo por precisar cuidar dos irmãos mais novos.

\section{DISCUSSÃO}

Os jogos, brinquedos e brincadeiras fazem parte do mundo da criança, e estão presentes na humanidade desde a antiguidade. A partir, principalmente, do Século XIX, o jogo foi tomado como objeto de investigação pelos cientistas, desde então se ampliou de formação significativa estudos sobre o fenômeno, demonstrando a sua importância no desenvolvimento da criança. Assim, a ludicidade passou a ser reivindicada para estar presente na Educação Infantil, considerando o importante papel que cumpre no processo de aprendizagem e formação da criança.

Quando afirmamos que a ludicidade é indispensável na Educação Infantil, não queremos dizer que estamos abandonando a seriedade e a importância dos conteúdos escolares a serem apresentados às crianças, pois as atividades lúdicas são essenciais para um desenvolvimento saudável e apreensão dos conhecimentos, visto que possibilita o desenvolvimento da percepção, da fantasia, da imaginação e dos sentimentos das crianças.

A educação lúdica contribui e influencia na formação da criança, possibilitando um crescimento sadio, um enriquecimento permanente, integrando-se ao mais alto espírito democrático enquanto investe em uma produção séria do conhecimento. A sua prática exige a participação franca, criativa, livre, crítica, promovendo a interação social e tendo em vista o 
forte compromisso de transformação e modificação do meio (ALMEIDA apud DALLABONA; MENDES, 2004, p. 9).

É importante ressaltar que não são somente os professores que reduzem o lúdico do universo infantil, mas também os pais, que deixam as crianças brincarem cada vez menos, por inúmeras razões, dentre elas, os problemas de espaço, segurança e, ainda, o excesso de atividades atribuídas durante a semana, tais como: escola, natação, computação, inglês, dança, pintura, ginástica, entre outras. Tudo isso, toma o tempo das crianças, e quando sobra tempo para brincar, elas estão cansadas e preferem assistir televisão ou brinquedos eletrônicos (DALLABONA; MENDES, 2004).

Destarte, compreende-se a vital importância da brincadeira como forma de aprendizagem, e o adulto que participa ativamente destas atividades lúdicas proporciona às crianças um maior desenvolvimento.

O hábito de brincar precisa ser cultivado no seio da família, pois, fortalece a formação do vínculo afetivo, melhorando as relações. Além disso, o jogo, a brincadeira, o faz de conta, estimulam a socialização, a inteligência, a criatividade, favorecendo o surgimento das possibilidades, como também, o reconhecimento das limitações e dificuldades (ZUCCOLOTTO, 2009, p.3).

Por tudo isso, a família constitui-se como fonte de aprendizagens, de interação e socialização e é por meio do brincar em parceria que a criança se desenvolve e estabelece ligações com o mundo, aprimorando suas relações e aprendizagens. No que diz respeito à escola, ela precisa repensar quem está educando, considerar e respeitar as necessidades e as culturas de cada criança, pois ao valorizar o jogo, o brinquedo e a brincadeira, a escola apresenta desafios e provoca pensamentos reflexivos à criança, fazendo com que ela aprenda e se desenvolva em todos os aspectos: social, cognitivo, relacional e pessoal.

\section{CONCLUSÃO}

As culturas da infância representam um campo de investigação que ainda necessita de muito aprofundamento, especialmente sobre o eixo "ludicidade". O brincar é fundamental para o desenvolvimento humano, mas, ainda é pouco valorizado e utilizado nos meios sociais, sobretudo no meio familiar e escolar. O contexto familiar e escolar são espaços essenciais para o desenvolvimento de experiências lúdicas, as quais consequentemente influenciarão diretamente na vida das crianças. 
No período da pesquisa, constatamos avanços em termos de discursos e práticas, todavia, para o alcance de resultados mais significativos e maior efetivação dos discursos na realidade é preciso mais condições físicas, temporais e materiais, ainda, cobranças coerentes com a legislação educacional e a produção científica atual. Deste modo, é preciso que as professoras aprofundem seus conhecimentos e enriqueçam as experiências lúdicas das crianças no contexto da Educação Infantil para que assim elas atinjam seu desenvolvimento pleno de modo eficaz.

Em relação aos pais/responsáveis das crianças, é necessário a valorização do tempo destinado à ludicidade dos filhos, já que estes estão a todo momento fantasiando, brincando, produzindo cultura e requerendo a sua presença no contexto das brincadeiras e jogos. Neste sentido, uma relação de diálogo entre e escola e comunidade pode favorecer um maior convencimento dos pais ou responsáveis sobre a ludicidade como prioridade na vida das crianças, ampliando assim seus esforços, que já não são poucos, para que as crianças brinquem mais, inclusive, com a sua participação.

\section{REFERÊNCIAS}

ANDRÉ, M. E. D. A. Tendências atuais da pesquisa na escola. Cadernos CEDES, Campinas, v. 18, n. 43, p.46-57, dez. 1997.

CUNHA, A. C. A investigação por questionário e entrevista: um exemplo prático. Braga: Editorial Magnólia, 2007.

DALLABONA, S. R.; MENDES, S. M. S. O lúdico na educação infantil. Revista de divulgação técnico científica do ICPG, v.1, n.4, jan/mar 2004.

DELGADO, A.C. C.; MÜLLER, F. Em busca de metodologias investigativas com crianças e suas culturas. Cadernos de Pesquisa, v. 35, n. 125, p.161-179, maio/ago. 2005.

MARCHI, R. C. O "ofício de aluno" e o "ofício de criança": articulações entre a sociologia da educação e a sociologia da infância. Rev. Portuguesa de Educação. v.23, n.1, p. 183-202. 2010.

SARMENTO, M. J. As culturas da infância nas encruzilhadas da 2a modernidade. Braga, Portugal. Universidade do Minho. Centro de Estudos da Criança (mimeo), 2002.

SARMENTO, M. J.; CERISARA, A. B. Crianças e Miúdos: perspectivas sociopedagógicas da infância e educação. Lisboa: Asa Editores S.A. 2004.

SARMENTO, M. J.; PINTO, M. As crianças e a infância: definindo conceitos, delimitando o campo. In: PINTO, M. SARMENTO, M. J. As crianças: contextos e identidades. Portugal, Centro de Estudos da Criança: Editora Bezerra, 1997. 
SILVA, M. O. L.; OLIVEIRA, S. S.; PEREIRA, V. A.; LIMA, M. G. S. B. Etnografia e Pesquisa Qualitativa: apontamentos sobre um caminho metodológico de investigação. Disponível em: <http://www.ufpi.br/subsiteFiles/ppged/arquivos/files/ VI.encontro.2010/GT.1/GT_01_15.pdf Acesso em: 07 de fevereiro de 2013.

ZUCCOLOTTO, S. de A. L. A desvalorização do brincar pela família do século XXI. Rev. Eletrônica de Divulgação Científica da Faculdade Don Domênico. 2a ed. Out/2009. 